\title{
Editorial
}

\section{Building Healthy Academic Communities in this Post-Pandemic Brave New World}

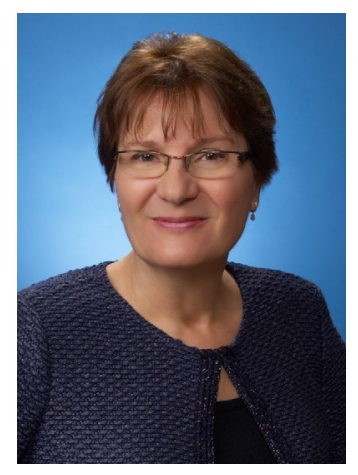

\section{Dianne Morrison-Beedy, PhD, RN, FNAP, FAANP, FAAN \\ Editor-in-Chief}

Whether it is looking at the world through the lens of Shakespeare, Huxley, or our current pandemic, one thing we understand is our need to be nimble as we look to the future. This agility requires flexibility of both mind and spirit. Academic communities have had to respond quickly to the need for virtual classrooms and learning experiences and for faculty and staff exchanges through zoom, teams, or other platforms. The vast majority did so quickly and with a dexterity that surprised many of us. Despite those successes, what we probably learned most was the need for us to be flexible in spirit - we learned that our mental and emotional parts needed attention and support as much as our masked, sanitized, and socially-distanced bodies needed "shoring up." Truly, in this brave new world, we learned that caring for our mental and emotional well-being was just as critical to getting us, and our students, through the pandemic as were vaccines and treatments. It took more than 6 feet apart, adequate bandwidth, and internet speed for academic communities to move forward. Caring, really caring, for ourselves and others was essential. As the new Editor-in-Chief of the National Consortium's Journal for Building Health Academic Communities (BHAC), I want to extend some caring to our reviewers, authors, staff, readers, and outgoing editor Meredith Wallace Kazer with a big thank you for all your contributions. Despite all the challenges and "character building experiences" of late, you have continued to give back to BHAC through your service. This has not gone unnoticed nor unappreciated by me. As we continue to move our Journal for BHAC forward, the articles in this issue remind us that many are suffering from mental health issues, stress, and overwhelmed feelings. Please continue to care for yourself and to reach out to colleagues and students who may be suffering silently. We are not out of the woods yet in this pandemic, but we are making progress. Please know that the research and innovative educational approaches you are developing to build healthy academic communities is critical for meeting our mission to provide academic communities with evidence-based strategies and resources to improve population health and well-being of the faculty, students, staff, alumni and the communities they serve. To this end, we plan to grow the Journal for BHAC in both depth and breadth with more contributions per issue and additional issues each year. So please consider this journal as an outlet for your work and encourage others to do so as well. As Editor-inChief, I am grateful for authors' contributions and the wise input from our reviewers who make each publication better and more useful to our readers. Yes, it is a brave new world out there, and we are excited about leaving our mark by making academic communities healthier through robust, relevant, and rigorous information for our readers. 